ВОЗМОЖНОСТИ

НАНОБИОКОМПОЗИТОВ ДЛЯ ЛЕЧЕНИЯ ДЕФЕКТОВ КОЖИ

ИСПОЛЬЗОВАНИЯ

Е. В. Зиновьев ${ }^{1}$, М. С. Асадулаев ${ }^{2}$, Д. В. Костяков ${ }^{1}$, К. Ф. Османов ${ }^{1}$, Р. Г. Стояновский ${ }^{2}$, Н. В. Смирнова ${ }^{3}$, А. С. Шабунин ${ }^{3}$, С. А. Лукьянов ${ }^{2}$

${ }^{1}$ ФГБВОУ ВО «Военно-медицинская академия имени С. М. Кирова» МО РФ, г. СанктПетербург, Россия

2 ФГБОУ ВО «Санкт-Петербургский государственный педиатрический медицинский университет» Минздрава РФ, г. Санкт-Петербург, Россия

3 ФГАОУ ВО «Санкт-Петербургский политехнический университет Петра Великого», г. Санкт-Петербург, Россия

\title{
THE POSSIBILITY OF USING THE POLYMER FOR THE TREATMENT OF FULL NANOBIOCOMPOSITES SKIN DEFECTS
}

\section{E. V. Zinov'ev' ${ }^{1}$, M. S. Asadulaev ${ }^{2}$, D. V. Kostyakov'1, K. F. Osmanov'1, R. G. Stoyanovskiy ${ }^{2}$, N. V. Smirnova ${ }^{3}$, A. S. Shabunin ${ }^{3}$, S. A. Luk'yanov ${ }^{2}$}

${ }^{1}$ S. M. Kirov Military Medical Academy the Russian Defense Ministry, Saint Petersburg, Russia

${ }^{2}$ Saint Petersburg State Pediatric Medical University, Saint Petersburg, Russia

${ }^{3}$ Peter the Great Saint Petersburg Polytechnic University, Saint Petersburg, Russia

Резюме. Представлены результаты экспериментальной оценки эффективности раневых покрытий на основе нановолокон хитозана и сополиамида при лечении полнослойных механических ран кожи. Разработана собственная оригинальная методика воспроизведения полнослойной механической раны кожи в эксперименте. Установлено, что применение раневых покрытий на основе алифатического сополиамида и хитозана позволяет существенно оптимизировать процессы репаративной регенерации в 
зоне полнослойного дефекта кожи, при этом констатировано сокращение сроков отторжения струпа и заживления ран соответственно на 7,5 и 11,2 сут (p $<$ 0,05). Показано, что использование покрытий на основе гидрогеля гиалуроновой кислоты также сопровождается достоверным ускорением гистеогенеза в зоне полнослойных дефектов кожи, сокращением продолжительности периода их окончательного заживления на 21\% (p < 0,05) (4 рис., 1 табл., библ.: 14 ист.).

Ключевые слова: алифатический сополиамид, гидрогель гиалуроновой кислоты, крысы Wistar-Kyoto, морфология раневого процесса, нанофибриллы хитина, планиметрия, полнослойные дефекты кожи, раневые покрытия, регенерация, хитозан.

\section{Статья поступила в редакцию 11.01.2017.}

Summary. The results of the experimental evaluation of the effectiveness of wound dressings based on chitosan nanofibres and copolyamide with treatment of full mechanical skin wounds. To develop their own original technique of mechanical reproduction all layers of the skin wounds in the experiment. It was found that application of wound dressings based on aliphatic copolyamide and chitosan can significantly optimize reparative regeneration processes in the area all layers of the skin defect, thus reducing the time stated scab rejection and wound healing, respectively, 7.5 and 11.2 days $(\mathrm{p}<0,05)$. It is shown that the use of coatings based on hyaluronic acid hydrogel is also accompanied by a significant acceleration in the zone histogenesis all layers of the blemishes, shortening the healing period of the final 21\% ( $\mathrm{p}<0,05)$ (4 figs, 1 table, bibliography: 14 refs).

Key words: aliphatic copolyamide, all layers of the skin defects, chitin nanofibrils, chitosan, hyaluronic acid hydrogel, morphology of wound healing, plane geometry, rats Wistar-Kyoto, regeneration, wound dressings.

\section{ВВЕДЕНИЕ}


Проблема лечения обширных полнослойных дефектов кожи, несмотря на широкий перечень доступных ранозаживляющих средств и раневых покрытий, в настоящее время остается важной медико-социальной проблемой $[1,2]$. Современные методы лечения обширных кожных дефектов включают использование как традиционных методик кожной пластики, асептических повязок с многокомпонентными антибактериальными мазями, раневых покрытий на основе синтетических и природных полимеров, ведение ран в условиях отрицательного давления, так и новых экспериментальных методов лечения, таких как культуры кератиноцитов, биотехнологические продукты, дермальные эквиваленты, фибробласты, мезенхимные стволовые клетки, скаффолды [3]. Результаты лечения с применением традиционных методик не всегда позволяют достичь удовлетворительных результатов [4]. Использование клеточных технологий в настоящее время проходит этапы регламентации и юридического внедрения в практику [5].

Материалы для тканевой инженерии должны обладать биосовместимостью, прогнозируемой резорбцией; кроме того, как сами материалы, так и продукты их биодеградации не должны быть цитотоксичными [6-8]. Для пролиферации клеток в объеме матрицы, формирования ткани, идентичной ткани реципиента необходимо наличие пор размером в десяткисотни микрометров. Перспективным полимером, который применяется для материалов биомедицинского назначения, является хитозан [9]. Важное свойство хитозана - то, что это биодеградируемый полимер, обладающий хорошей биосовместимостью. Продукты биодеградации хитозана нетоксичны и включаются в естественные биохимические реакции организма [10]. Нановолокна хитозана обладают гемостатическим и бактерицидным свойствами [11].

В лаборатории «Полимерные материалы для тканевой инженерии и трансплантологии» Санкт-Петербургского политехнического университета Петра Великого нами были разработаны раневые покрытия, состоящие из двух слоев: внешнего, на основе нановолокн алифатического сополиамида, и 
внутреннего, на основе хитозана. Наружный слой обеспечивает механическую защиту раны от проникновения бактериальных агентов, уменьшает потерю жидкости за счет испарения с раневой поверхности. Внутренний слой стимулирует пролиферацию эпителиальных клеток и способствует их распространению по раневой поверхности, тем самым ускоряя процессы репарации и регенерации раны $[12,13]$. Впоследствии внутренний слой подвергается биоразложению, а наружный отпадает с элементами струпа, не травмируя вновь образованные ткани. Внедрение хитозан-сополиамидных раневых покрытий в клиническую практику позволит уменьшить продолжительность периода заживления ран, снизит частоту инфекционносептических осложнений, а также за счет двух вышеуказанных факторов снизит сроки госпитализации [14].

\section{ЦЕЛЬ ИССЛЕДОВАНИЯ}

Целью исследования является сравнительная оценка эффективности раневого покрытия на основе нановолокон хитозана и сополиамида при лечении полнослойных дефектов кожи.

\section{МАТЕРИАЛЫ И МЕТОДЫ ИССЛЕДОВАНИЯ}

Эксперимент выполнен на 24 самцах крыс линии «Wistar-Kyoto» весом 230-250 г. Животные были разделены на три группы исследования по 8 особей с учетом методики ведения ран. В первой (опытной) лечение ран осуществлялось с применением экспериментальных раневых покрытий из алифатического сополиамида и хитозана (производство Санкт-Петербургского политехнического университета Петра Великого). Обладает свойствами биосовместимости, биорезорбируемости и бактерицидности. Хитозан полимер D-глюкозамина, растворимый в органических и неорганических кислотах (кроме серной). В работе применялся хитозан (производство ООО «Биопрогресс») со средневесовой молекулярной массой 200 кДа и степенью деацетилирования 80\%. Во второй группе (сравнения) на раны проводилась 
аппликация раневых покрытий на основе гидрогеля гиалуроновой кислоты (ООО «ДЖИ-Групп», Российская Федерация). В контрольной группе лечение ранее не проводилось.

Полнослойный дефект кожи воспроизводился по собственной, оригинальной методике. Данный способ позволяет избежать преждевременного закрытия ран первичным натяжением, достоверно оценить эффективность средств для заживления ран. Ингаляционный наркоз животных осуществляется эфиром. После депиляции кожи спины и фиксации сегментов конечностей животного к лабораторному столу область операционного поля обрабатывается антисептическим раствором. Разметка участка для иссечения выполняется раствором йода. Площадь моделируемой раны составляет 32 см $^{2}$ прямоугольник со сторонами 8 и 4 см (10\% от площади тела животного). Кожные края раны фиксируются узловыми кожно-мышечными инвертирующими швами к собственной фасции (рис. 1). Первый прокол кожи осуществляется со стороны раны, второй — в фасции и подлежащих мышцах спины, после чего инструментальным способом завязывается узел, который погружается в рану. Узлы накладываются с интервалом 1 см (32 узла).

Разработанная методика позволяет обеспечить устойчивый контакт исследуемых ранозаживляющих средств и их плотную фиксацию к раневой поверхности на протяжении всего эксперимента. Аппликация раневых покрытий выполнялась после воспроизведения раны (рис. 2). В качестве дополнительной фиксации раневых покрытий к краям раны использовали кожный клей «Dermabond» (Германия). C целью предотвращения контаминации раневой поверхности вводили Cephazolin 500 мг однократно. В течение всего экспериментального исследования (4 нед) проводился ежедневный контроль процесса регенерации моделированной раны до полного ее заживления.

Оценка эффективности ранозаживляющих препаратов и фотографирование раны проводились ежедневно. Выполняли внешний осмотр ран, отмечали характер отделяемого, наличие и вид грануляций, фиксировали 
сроки отторжения струпа и заживления раневых поверхностей (см. рис. 3). Планиметрическим методом Л. Н. Поповой определяли площадь раны и индекс заживления по формуле (Фенчин К. И., 1979)

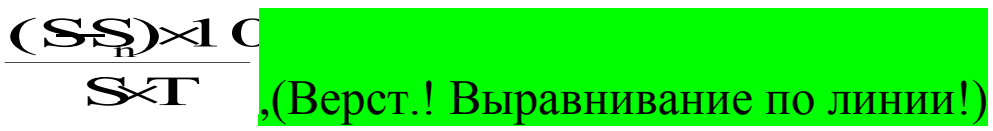

где $\mathrm{S}$ - площадь раны при предыдущем измерении, мм $^{2} ; \mathrm{S}_{\mathrm{n}}$ - площадь раны при данном измерении, мм²; Т — интервал между измерениями, сут.

Отбор биоптатов для гистологического исследования осуществляли на 3 и, 7, 12, 15, 21, 28-е сут лечения. Биоптаты фиксировали в 10\% растворе нейтрального формалина с последующей проводкой через спирты восходящей концентрации (30-100\%) и заливкой в парафин. Парафиновые срезы окрашивали гематоксилином и эозином с дальнейшим их исследованием методом световой микроскопии.

Обработка полученных результатов проводилась в соответствии с общепринятыми методами вариационной статистики. Критерием достоверности считали величину $\mathrm{p}<0,05$.

\section{РЕЗУЛЬТАТЫ И ОБСУЖДЕНИЕ}

Установлено, что исследуемые образцы ранозаживляющих средств характеризуются значительной адгезивной способностью, при этом покрытия на основе алифатического сополиамида и хитозана обладают высокой адгезией, что выражается в их прочном и плотном контакте с раневой поверхностью на 3-7-е сут наблюдения. Покрытия на основе гидрогеля гиалуроновой кислоты in vivo характеризовались менее выраженными адгезивными свойствами, вследствие чего возникала необходимость в их дополнительной фиксации.

Данные табл. 1 и рис. 4 свидетельствуют о том, что применение раневых покрытий на основе алифатического сополиамида и хитозана позволило существенно оптимизировать процессы репаративной регенерации в зоне полнослойного дефекта кожи, при этом констатировано сокращение сроков 
отторжения струпа и заживления ран соответственно на 7,5 и 11,2 сут (p < 0,05) по сравнению с группой животных, лечение ран которых не проводилось. Использование покрытий на основе гидрогеля гиалуроновой кислоты также сопровождалось ускорением гистеогенеза в зоне полнослойных дефектов кожи, сокращением продолжительности периода их окончательного заживления. В этой группе экспериментальных животных процессы отторжения струпа завершались к 16,3 сут, а процессы окончательного заживления ран — к 24,1 сут. При гистологическом исследовании биоптатов ран на 18-е сут наблюдения установлено, что наибольшее количество новообразованных сосудов микроциркуляторного русла (25 ед. в поле зрения) констатировано в группе животных, у которых лечение ран проводилось с применением раневых покрытий на основе гидрогеля гиалуроновой кислоты. Аналогичный показатель с использованием раневых покрытий на основе сополиамида и хитозана соответствовал 13 ед. в поле зрения, т.е. меньше на 48\% (p < 0,05).

Таблицьа 1

\section{Планиметрическая оценка результатов применения} ранозаживляющих средств

\begin{tabular}{|c|c|c|c|c|}
\hline \multirow{2}{*}{$\begin{array}{l}\text { Группы } \\
\text { исследования }\end{array}$} & \multicolumn{2}{|c|}{$\begin{array}{l}\text { Средний срок периода } \\
(\mathbf{M} \pm \mathbf{m}), \text { сут }\end{array}$} & \multirow{2}{*}{$\begin{array}{l}\text { Количество } \\
\text { микрососудов } \\
\text { в поле зрения } \\
(\text { ув. ×40) }\end{array}$} & \multirow{2}{*}{$\begin{array}{l}\text { Клеточный } \\
\text { состав } \\
\text { (фибробласты/ } \\
\text { нейтрофилы) }\end{array}$} \\
\hline & $\begin{array}{l}\text { отторжение } \\
\text { струпа }\end{array}$ & $\begin{array}{l}\text { заживление } \\
\text { ран }\end{array}$ & & \\
\hline $\begin{array}{l}\text { Хитозан- } \\
\text { сополиамид }\end{array}$ & $14,1 \pm 0,8^{1}$ & $19,2 \pm 0,6^{1,2}$ & $13 \pm 1,5^{2}$ & $+++/-$ \\
\hline $\begin{array}{l}\text { Гиалуроновая } \\
\text { кислота }\end{array}$ & $16,3 \pm 0,4^{1}$ & $24,1 \pm 0,2^{1}$ & $25 \pm 3$ & $++/-$ \\
\hline Без лечения & $21,6 \pm 2,1$ & $30,4 \pm 2,3$ & $15 \pm 2$ & $-/+++$ \\
\hline \multicolumn{5}{|c|}{$\begin{array}{l}\text { Примечание. }{ }^{1}-\text { достоверно }(\mathrm{p}<0,05) \text { по сравнению с контролем (без } \\
\text { лечения }){ }^{2} \text { - достоверно }(\mathrm{p}<0,05) \text { по сравнению с гиалуроновой кислотой. }\end{array}$} \\
\hline
\end{tabular}


Полученные результаты свидетельствуют о том, что применение полимерных покрытий на основе алифатического сополиамида и хитозана, а также гидрогеля гиалуроновой кислоты позволяет достоверно ускорить процесс регенерации раневого дефекта

\section{ВЫВОДЫ}

В ходе экспериментального исследования было установлено, что применение полимерных покрытий на основе алифатического сополиамида и хитозана и гидрогеля гиалуроновой кислоты позволяет ускорить процесс регенерации полнослойного раневого дефекта кожи на 20\% (p < 0,05), а также сокращает продолжительность общего периода заживления механических повреждений кожных покровов. Покрытия на основе гиалуроновой кислоты более эффективно стимулируют рост микрососудов, способствуя сокращению сроков развития грануляционной ткани и подготовки ран к аутодермопластике.

\section{ЗАКЛЮЧЕНИЕ}

Предложенные биополимерные покрытия на основе алифатического сополиамида и хитозана и гидрогеля гиалуроновой кислоты могут стать конкурентоспособной альтернативой аналогам зарубежного производства. Методика наложения раневых покрытий отличается технической простотой, что создает предпосылки для их широкого внедрения в клиническую практику. Авторы благодарят Российский научный фонд (грант № 14-33-00003) за финансовую поддержку в проведении исследований.

\section{СПИСОК ЛИТЕРАТУРЫ / REFERENCES}

1. Suprun A. S. Improved methods of early diagnosis of tissue viability when scalped wounds limbs. Meditsina neotlozhnykh sostoyaniy. 2016; 6 (77): 85-9. Russian (Супрун A. C. Усовершенствование методов ранней диагностики 
жизнеспособности тканей при скальпированных ранах конечностей. Медицина неотложных состояний. 2016; 6 (77): 85-9).

2. Yakovlev S. V. Dermatology and plastic surgery for burns and post-burn brush deformation. Fundamental'nye issledovaniya. 2013; 1 (6): 1253-9. Russian (Яковлев С. В. Кожно-пластические операции при ожогах и послеожоговой деформации кисти. Фундаментальные исследования. 2013; 1 (6): 1253-9).

3. Pasichnyi D. A. Predictive test the viability of the flap and the preparation of the tissues to the "Italian" plastic with limb defects. Klinicheskaya khirurgiya. 2014; 4: 49-52. Russian (Пасичный Д. А. Прогностический тест жизнеспособности лоскута и подготовка тканей к «итальянской» пластике при дефектах конечностей. Клиническая хирургия. 2014; 4: 49-52).

4. Zinov'ev E. V., Rakhmatullin $R . \quad R$., Apchel A. $V$. Bioplastic dermatoterapevticheskie system based hydrocolloid and hyaluronic acid peptide complex. Vestn. Ros. voyen.-med. akad. 2014; 1 (45): 147-51. Russian (Зиновьев E. B., Рахматуллин P. P., Апчел А. В. Биопластические дерматотерапевтические системы на основе гидроколлоида гиалуроновой кислоты и пептидного комплекса. Вестн. Рос. воен.-мед. акад. 2014; 1 (45): 147-51).

5. Kalmykova N. V., Spichkina O. G., Ellinidi V. N. Bioplastic material based on hyaluronic acid as a matrix for the creation of cell express biomedical products for skin repair. Geny i kletki. 2014; 9; 2: 68-75. Russian (Калмыюква Н. В., Спичкина О. Г., Эллиниди B. Н. Биопластический материала на основе гиалуроновой кислоты как матрица для создания биомедицинских клеточных экспресс-продуктов для восстановления кожи. Гены и клетки. 2014; 9; 2: 68-75).

6. Gol'tsev A. N., Rassokha I. V., Dubrava T. G., Ostankova L. V., Ostankov M. V., Gordienko E. A., Safonov V. I., Zykova A. V. The use of nanocomposite coatings in cultivation techniques multipotent mesenchymal stromal cells. Geny i kletki. 2013; 8 (1): 46-50. Russian (Гольщев А. Н., Рассоха И. В., Дубрава Т. Г., Останкова Л. В., Останков М. В., Гордиенко Е. А., Сафонов В. И., Зыкова А. В. Использование нанокомпозитных покрытий в технологиях культивирования 
мультипотентных мезенхимных стромальных клеток. Гены и клетки. 2013; 8 (1): 46-50).

7. Shcheblykina A. V., Mishchenko P. V., Kumeyko V. V. Biocompatible degradable materials based on pectin for tissue engineering: local tissue reaction after subcutaneous implantation. Tikhookeanskiy meditsinskiy zhurnal. 2013; 2 (52): 13-7. Russian (Щеблькина А. В., Мищенко П. В., Кумейко В. В. Биосовместимые деградируемые материалы на основе пектинов для тканевой инженерии: местная реакция тканей при подкожной имплантации. Тихоокеанский медицинский журнал. 2013; 2 (52): 13-7).

8. Busilacch A., Gigante A., Mattioli-Belmonte M. Chitosan stabilizes platelet growth factors and modulates stem cell differentiation toward tissue regeneration. Carbohydrate Polymers. 2013; 98 (1): 665-76.

9. Leceta I., Guerrero P. Functional properties of chitosan-based films. Carbohydrate Polymers. 2013; 93 (1): 339-46.

10. Croisier F., Jérôme $C$. Chitosan-based biomaterials for tissue engineering. European Polymer Journal. 2013; 49 (4): 780-92.

11. Elsabee M. Z, Abdoub E. S. Chitosan based edible films and coatings: A review. Mater. Sci. Eng. C. Mater. Biol. Appl. 2013; 33 (4): 1819-41.

12. Anitha A., Sowmyaa S., Sudheesh Kum P. T. Chitin and chitosan in selected biomedical applications. Progress in Polymer Science. 2014; 39; 9: 1644-67.

13. Shukla S. K., Mishra A. K., Arotiba O. A. Chitosan-based nanomaterials: A state-of-the-art review. Int. J. Biol. Macromol. 2013; 59: 46-58.

14. Abdelgawad A. M., Hudsona S. M., Rojas O. J. Antimicrobial wound dressing nanofiber mats from multicomponent (chitosan/silver-NPs/polyvinyl alcohol) systems. Carbohydrate Polymers. 2014; 100: 166-78.

\section{ИНФОРМАЦИЯ ОБ АВТОРАХ INFORMATION ABOUT AUTHORS}


Зиновьев Евгений Владимирович - докт. мед. наук профессор, старший научный сотрудник научно-исследовательской лаборатории (военной хирургии) научно-исследовательского центра, ФГБВОУ ВО «Военномедицинская академия имени С. М. Кирова» МО РФ, 194044, Россия, г. СанктПетербург, ул. Академика Лебедева, д. 6, конт. тел.: +7(812)9836392

Zinov'ev Evgeniy V. - M. D., D. Sc. (Medicine), Prof., senior researcher, S. M. Kirov Military Medical Academy the Russian Defense Ministry, 6, Akademika Lebedeva str., Saint Petersburg, Russia, 194044, cont. phone: $+7(812) 9836392$ Асадулаев Марат Сергеевич - клинический ординатор, ФГБОУ ВО «СанктПетербургский государственный педиатрический медицинский университет» Минздрава РФ, 194100, Россия, г. Санкт-Петербург, Литовская ул., д. 2г, конт. тел.: +7(964)3289752

Asadulaev Marat S. - clinical intern, Saint Petersburg State Pediatric Medical University, 2g, Litovskaya str., Saint Petersburg, Russia, 194100, cont. phone:+7(964)3289752.

Костяков Денис Валерьевич - ассистент кафедры патологической физиологии, ФГБВОУ ВО «Военно-медицинская академия имени С. М. Кирова» МО РФ, 194044, Россия, г. Санкт-Петербург, ул. Академика Лебедева, д. 6, конт. тел.: +7(981)8972004

Kostyakov Denis V. - assistant of Pathological Physiology Department, S. M. Kirov Military Medical Academy the Russian Defense Ministry, 6, Akademika Lebedeva str., Saint Petersburg, Russia, 194044, cont. phone: +7(981)8972004

Османов Камил Фахрутдинович - внешний соискатель кафедры патологической физиологии, ФГБВОУ ВО «Военно-медицинская академия имени С. М. Кирова» МО РФ, 194044, Россия, г. Санкт-Петербург, ул. Академика Лебедева, д. 6

Osmanov Kamil F. - external Competitor of Pathological Physiology Department, S. M. Kirov Military Medical Academy the Russian Defense Ministry, 6, Akademika Lebedeva str., Saint Petersburg, Russia, 194044 
Стояновский Роман Григорьевич - клинический ординатор, ФГБОУ ВО «Санкт-Петербургский государственный педиатрический медицинский университет» Минздрава РФ, 194100, Россия, г. Санкт-Петербург, Литовская ул., д. 2г

Stoyanovskiy Roman G. - clinical intern, Saint Petersburg State Pediatric Medical University, 2g, Litovskaya str., Saint Petersburg, Russia, 194100

Смирнова Наталья Владимировна - канд. биол. наук, научный сотрудник научно-исследовательской лаборатории «Полимерные материалы для трансплантологии и тканевой инженерии», ФГАОУ ВО «Санкт-Петербургский политехнический университет Петра Великого», 194064, Россия, г. СанктПетербург, ул. Политехническая, д. 29.

Smirnova Natal'ya V. - candidate of biological sciences, Peter the Great Saint Petersburg Polytechnic University, 29, Politekhnicheskaya str., Saint Petersburg, Russia, 194064

Шабунин Антон Сергеевич - клинический ординатор, ФГАОУ ВО «СанктПетербургский политехнический университет Петра Великого», 194064, Россия, г. Санкт-Петербург, ул. Политехническая, д. 29

Shabunin Anton S. - clinical intern, Peter Great Saint Petersburg State Polytechnic University, 29, Politekhnicheskaya str., Saint Petersburg, Russia, 194064

Лукьянов Сергей Андреевич - клинический ординатор, ФГБОУ ВО «СанктПетербургский государственный педиатрический медицинский университет» Минздрава РФ, 194100, Россия, г. Санкт-Петербург, Литовская ул., д. 2г

Luk'yanov Sergey A. - clinical, intern, Saint Petersburg State Pediatric Medical University, 2g, Litovskaya str., Saint Petersburg, Russia, 194100 